\title{
Molecular Characteristics of the Surfactants Con- sidered
}

Ionic surfactants are described using the following molecular characteristics:

\begin{tabular}{cccccccc}
\hline Ionic Surfactant & $n_{\mathrm{t}}$ & $a_{\mathrm{h}}\left[\AA^{2}\right]$ & $l_{\mathrm{h}}[\AA]$ & $d_{z}[\AA]$ & $z_{\mathrm{A}}$ & $z_{\mathrm{C}}$ & $r_{\mathrm{C}}[\AA]$ \\
\hline $\mathrm{C}_{i} \mathrm{TAB}$ & $i-1$ & 32.0 & 5.76 & 2.5 & +1 & -1 & 2.10 \\
$\mathrm{NaC}_{10} \mathrm{~S}$ & 9 & 25.0 & 6.27 & 3.7 & -1 & +1 & 2.18 \\
\hline
\end{tabular}

where $n_{\mathrm{t}}$ is the number of carbon atoms in the hydrophobic portion of the tail, $a_{\mathrm{h}}$ is the cross-sectional area of the head, $l_{\mathrm{h}}$ is the length of the ionic surfactant head, $d_{z}$ is the distance from the tail (as measured from the first hydrophobic carbon atom) to the location of the charge in the head, $z_{\mathrm{A}}$ is the valence of the head, $z_{\mathrm{C}}$ is the valence of the counterion, and $r_{\mathrm{C}}$ is the hydrated radius of the counterion.

Two molecular characteristics are required to describe nonionic surfactants, $n_{\mathrm{t}}$ and $a_{\mathrm{h}}$. For $\mathrm{C}_{i} \mathrm{E}_{j}$ surfactants, $n_{\mathrm{t}}$ is $(i-1)$ and $a_{\mathrm{h}}$ is estimated using the following temperature-dependent equation:

$$
a_{\mathrm{h}}(j, T)=a_{\mathrm{h} 0}\left[1-H\left(T-T_{0}\right)\right]\left(\frac{j}{6}\right)^{z}
$$

where $j$ denotes the number of ethylene oxide units, $T$ is the tempera-

ture in $\mathrm{K}, T_{0}$ is $273 \mathrm{~K}, a_{\mathrm{h} 0}=49.4 \AA^{2}$ denotes the cross-sectional area of a hexa(ethylene oxide) head $(j=6)$ at $T_{0}, H=0.0057 \mathrm{~K}^{-1}$ models the temperature dependence of the head area due to hydration effects, and $z=0.8$ models the scaling of the head cross-sectional area with $j$. 